\title{
Materiais, saberes artesanais e práticas pluriversais na construção de uma MAterioteca virtual
}

Luiza Gomes Duarte de Farias;

Letícia Barros Dantas;

Raquel Gomes Noronha

resumo:

O artigo em questão propõe uma reflexão sobre as práticas com os materiais no campo do design a partir da construção de uma MAterioteca virtual - um acervo de materiais (DANTAS E BERTOLDI, 2016) para o reconhecimento de saberes artesanais do Maranhão. Ao tecer um diálogo com o antropólogo britânico Tim Ingold (2011), acionamos os conceitos de conhecimento classificatório e conhecimento narrativo vinculados à noção de saber tácito (SPINUZZI, 2005) a fim de especular sobre a decolonialidade de saberes (TUNSTALL, 2013) e práticas orientadas para o pluriverso (ESCOBAR, 2016), tópicos estes que servem ao exercício de análise sobre a metodologia empregada e os resultados materializados no acervo. Por fim, elabora possibilidades pluriversais nas relações travadas com os materiais em via de exercitar a valorização de uma multiplicidade de conhecimentos e ontologias.

\section{palavras-chave:}

MAterioteca; artesanato; conhecimento narrativo; saber tácito; pluriverso 


\section{Introdução}

Este artigo apresenta reflexões sobre o processo de construção de uma MAterioteca ${ }^{1}$ vinculada ao Núcleo de Pesquisas em Inovação, Design e Antropologia (NIDA) da Universidade Federal do Maranhão, no que tange à produção, intercâmbio e divulgação de conhecimentos acadêmicos em diálogo com conhecimentos tácitos, retomando a questão do design em diálogo com o artesanato.

No curso de onze anos de pesquisa em comunidades produtoras de artesanato no Maranhão, realizadas pelo NIDA, foram percebidas diversas lacunas e potencialidades nas dezesseis cadeias produtivas mapeadas, como a da produção de louças em Itamatatiua, o tear da fibra de buriti em Santa Maria, o fazer das caretas de cazumbá em Matinha, entre muitas outras. O percurso de trabalho colaborativo estabelecido pelo núcleo foi responsável por trazer à tona uma série de empecilhos relacionados à comercialização dos produtos artesanais, como a carência de formas de divulgação realizadas por meio da tecnologia, como registramos em publicações anteriores (NORONHA, 2011; NORONHA, 2015; NORONHA et al 2017). Tais lacunas evidenciaram a importância de táticas que busquem facilitar a comunicação entre potenciais consumidores, majoritariamente urbanos e tendo as tecnologias da informação ao seu dispor, com estas comunidades criativas locais (MANZINI, 2017), aumentando, dessa forma, a comercialização dos artefatos e a ampliação do intercâmbio entre saberes e fazeres, mobilizando a etapa de logística referente às cadeias de valores, conforme disposto em nossa recente publicação (SILVA et al, 2020).

Além de implicar num estreitamento espacial, a criação de plataformas digitais que facilitem o comércio de produtos artesanais também possui o poder de funcionar de modo a dar maior visibilidade às formas de saberes tradicionais do território maranhense. O projeto de construção da MAterioteca, isto é, um acervo virtual para divulgação de amostras de materiais, processos e produtos artesanais do Maranhão, conforme caracterizam as autoras Dantas e Bertoldi (2016), deve levar em consideração que as pessoas acessem facilmente a amostra desejada, trazendo informações sobre o material, consultado em meio a um universo de elementos catalogados.

Assim, buscamos atuar de forma a mediar processos culturais entre os grupos produtivos e a sociedade em geral, tangibilizando conceitos e produzindo sentidos, como Manzini nos orienta quanto às atuações contemporâneas de designers (MANZINI, 2017). A favor de uma conscientização à respeito da manutenção das cadeias de valor artesanais, a plataforma conta uma história expressa em palavras e imagens que evocam o local, os artesãos e artesãs e os processos produtivos pautados em materiais, distanciando-se do método quantitativo e classificatório seguido por boa parte das materiotecas existentes para sistematizar materiais e processos, como observamos durante a pesquisa de similares em outras materiotecas (SILVA et al, 2020).

Dessa forma, o artigo em questão expõe, inicialmente, o processo de construção da MAterioteca, evidenciando as etapas projetuais e como ocorreu a sistematização das informações oriundas de pesquisas anteriores (NORONHA et al, 2017) realizadas em comunidades produtivas de artesanato no Maranhão. Em seguida, propomos uma reflexão sobre como pensar a comunicação de conhecimentos sobre materiais e processos para além da classificação de forma a ressaltar o conhecimento advindo da relação entre as artesãs e artesãos, os materiais e o território em que habitam, como o antropólogo britânico Tim Ingold nos propõe (INGOLD, 2011; 2015).

Ressaltamos também o papel das Tecnologias da Informação e Comunicação (VELOSO et. al, 2018), que se manifestam como ferramentas para dar maior espaço à estas narrativas, mobilizando cadeias produtivas e refletindo sobre novos modos de fortalecer a aproximação com saberes tradicionais no contexto acadêmico.

Por fim, serão exibidos os resultados do projeto de construção da MAterioteca e levantados questionamentos sobre novas formas de fazer design, salientando a importância de práticas que especulam sobre processos decoloniais e situados no campo, conforme nos inspiram a designer e antropóloga Dori Tunstall (2013) e o antropólogo Arturo Escobar (2016).

\footnotetext{
${ }^{1}$ A MAterioteca (a letras iniciais em maiúsculo fazem referência à sigla do estado do Maranhão) encontra-se disponível em www.materiotecaufma.com.br e foi financiada pelo edital Bolsa de Produtividade em Pesquisa da FAPEMA e pelo edital de Bolsas de Extensão da PROEXCE-UFMA, por meio do projeto Iconografias do Maranhão. Somos gratas às instituições pelo incentivo.
} 


\section{Conhecimento classificatório, conhecimento narrativo e conhecimento tácito}

Para nortear a reflexão aqui proposta, trazemos os conceitos de conhecimento classificatório e conhecimento narrativo, elaborados por Ingold (2015, p. 232), que auxiliam no entendimento sobre a sistematização de materiais e processos na construção da MAterioteca. Por conhecimento classificatório, depreende-se que os modos de conhecer as coisas obedecem à conceituação e classificação de suas propriedades, associando cada elemento encontrada à uma classe de elementos com as mesmas características orientadas do mais específico para o mais generalizado. Sendo assim, o conhecimento por meio da classificação é vertical, hierárquico, descontextualizado e busca assimilar as coisas que habitam o mundo como meros objetos, destituídos de movimento e vida.

Ashby e Johnson (2002) argumentam que a importância de se pesquisar os materiais para além de suas propriedades, para além daquilo que Ingold denomina como conhecimento classificatório, reside no fato que a relação entre as pessoas e os materiais são produzidos a partir de interpretações e geração de sentidos e significado das coisas, criando laços para além da materialidade, das combinações químicas e físicas que compõem os materiais. Assim, nas palavras dos autores, os materiais ganham vida, fazendo parte do imaginário e do arcabouço simbólico das sociedades.

Assim, um processo produtivo inclui a criatividade, a imaginação, a memória e a colaboração simbólica em um mundo em movimento, em que a experimentação prática com os materiais é um importante ponto a ser acionado por designers, como observam Karana (2010), Lima et al (2019) e Noronha e Sólis (2019).

Seguindo com a argumentação proposta por Ingold (2015), essa forma de trazer a subjetividade dos materiais é o que o autor denomina por conhecimento narrativo, que se constrói de forma atencional com as coisas que habitam o mundo, dando ênfase às relações que se traçam em contextos situados, o que, para o autor, é o que constitui uma história. É uma forma de assimilação aberta e entrelaçada à vida em um processo ativo de rememoração.

Possibilitar a divulgação de conhecimentos sobre os materiais e processos envolvidos no trabalho artesanal implica em não tornar como única finalidade a classificação a partir de seus atributos intrínsecos, a fim de que isto auxilie como ferramenta metodológica em projetos de design. Necessita-se, a princípio, dedicar atenção à história das relações que guiaram os materiais até o momento de captura, isto é, a sua definição num sistema classificatório, já que as coisas habitam um mundo de movimento e devir, como reforça o autor (INGOLD, 2012).

Da mesma maneira, trazemos a discussão sobre a diferenciação entre materialidade e materiais, já que no mundo da vida os objetos e sua suposta materialidade são entendidos como "coisas" que seguem em fluxo, isto é, são tidos como um aglomerado de fios vitais, algo em constante estado de transformação (INGOLD, 2012). Nessa perspectiva, essa divisão implica considerar que os materiais se distanciam dos processos que o vieram a constituir e permanecem continuamente a transformá-los e vice-versa. Semelhantemente, opõe-se à visão do modelo hilemórfico de pensamento, que pressupõe o processo criativo como um meio de impor forma à matéria, priorizando os produtos que se originam desses processos, ou seja, a busca pela materialidade do objeto como o objetivo final.

Outro conceito importante para a discussão é a importância do conhecimento tácito em nossa abordagem, definido por Spinuzzi como um tipo de conhecimento difícil de ser descrito e formalizado e que, por isso, tende a ser ignorado (SPINUZZI, 2005, p.165); é o conhecimento apreendido por meio da oralidade, da observação das técnicas corporais, como nos ensina Mauss (2009), e é portanto, aquele sem registro escrito.

Os campos da antropologia, da arqueologia e mais recentemente o do design já se propuseram aos estudos da cultura material como forma de entender as culturas e sociedades. Contudo, como o próprio nome da abordagem reforça, as investigações se lançam sobre os aspectos materiais. A antropóloga Manuela Carneiro da Cunha (2009) discute em profundidade a relação dos conhecimentos tradicionais e os conhecimentos especializados, e como o segundo se apropria do primeiro a partir de suas lógicas classificatórias e direcionadas às propriedades, como argumentam os autores e autoras que aqui acionamos.

Assim, nossa abordagem na MAterioteca busca trazer essas outras histórias, a partir das vozes e da tangibilização dos conhecimentos narrativos construídos pelas artesãs e artesãos em diálogos com as práticas estabelecidas de forma localizada. Os conhecimentos sobre os lugares, as relações subjetivas e a valorização do saber-fazer em suas relações cosmológicas são táticas que o NIDA 
aciona em suas pesquisas disponibilizadas na MAterioteca para discutir as hierarquias de saberes, depreendendo-se de um paradigma de verdade absoluta na construção dos saberes científicos, como aponta Kuhn (1974).

Essa abordagem que valoriza o saber relacional dos praticantes habilidosos - aqueles que fazem e possuem a habilidade do fazer construída pela vivência (INGOLD, 2011) — busca aproximar-se das narrativas que emergem da relação do artesão com os materiais, em seus devidos ambientes, possibilitando que o contar dessas histórias encontrem correspondência no modo como as designers exercem suas práticas projetuais, crescendo em conhecimento relacional com o fluxo das coisas, dos materiais, da produção do conhecimento, superando a noção de universalidade da ciência rumo ao pluriverso, conceito acionado por Arturo Escobar (2016) para refletir sobre a decolonialidade no campo do design.

Figuras 1 e 2 - Os artesã(o)s contando por meio de seu fazer com os materiais.

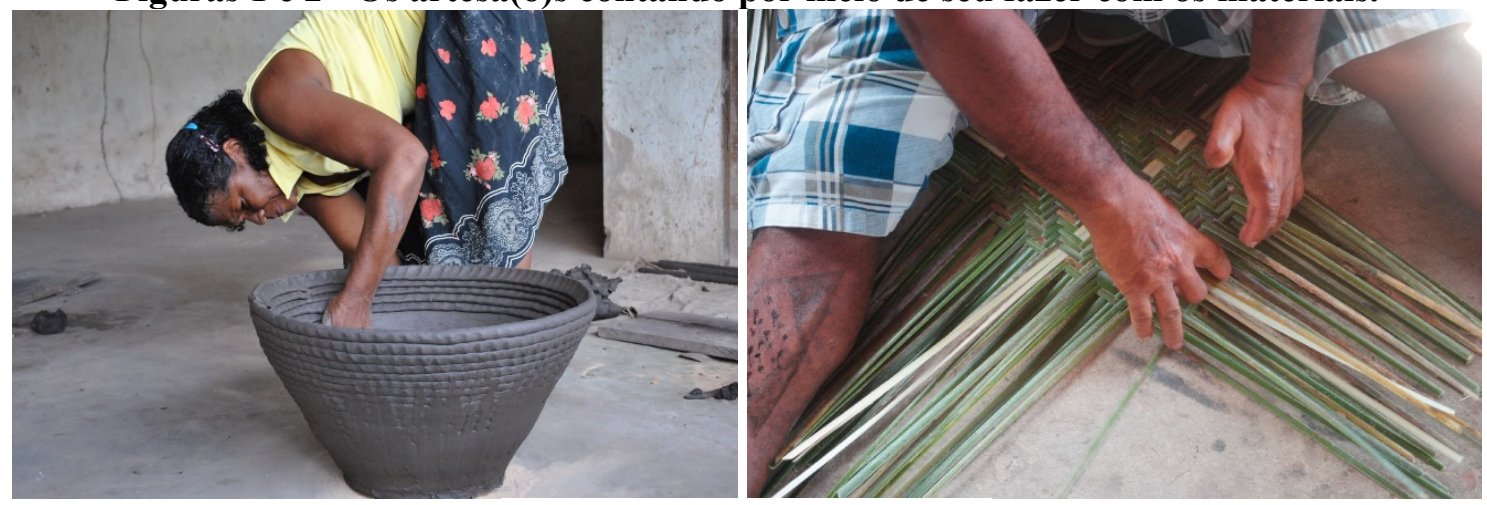

-Fonte: Acervo da MAterioteca.

\section{Da decolonidade dos saberes}

A construção de uma materioteca orientada para o artesanato envolve a abertura de um espaço para a ampliação do conhecimento sobre práticas tradicionais de fazer no campo do design e outros campos projetuais. Desse modo, pensar a comunicação de fazeres que compõem um território fornece uma reflexão sobre a forma que usualmente se concebe uma metodologia em projetos de design.

O modo como se estruturou o design moderno se atém a uma ideia de projeto extremamente alheia às demandas do território em que se encontra, avessa às contribuições do artesanato e aos conhecimentos não especializados (SOUZA LEITE, 2006; ANASTASSAKIS, 2014), constituindo-se como uma base de ensino de caráter eurocêntrico, que se utiliza de um modo de transmissão de conhecimento hierárquico e fechado, capaz de moldar nossas visões de mundo, afetos e corporeidades. É necessário, portanto, tornar mais íntimo à realidade daquele que projeta a relação com o ambiente em que ele se insere, sendo o estreitamento com o fazer artesanal, a raiz originária do que se concebe como design, uma ferramenta de decolonização dos nossos modos de aprendizado (TUNSTALL, 2013).

A percepção de que as práticas artesanais envolvem certos aspectos, de um lado, a atencionalidade com os materiais do mundo, numa prática criativa ligada à improvisação e à experimentação como Ingold $(2011 ; 2012 ; 2018)$ nos propõe, e de outro, a questão da memória, do imaginário e da preservação de saberes tradicionais, exige a formulação de uma estrutura distinta de acervo. Classificar é dividir, discernir entre cada unidade do mundo, romper com as linhas de intersubjetividade que elas carregam em prol da criação de compartimentos dentro dos quais trancálas, inertes no interior de uma ideia de enclausuramento epistemológico.

Ainda sim, no exercício de identificação em meio à alteridade com o intuito de delimitar a diferença, podemos considerar que se lida com uma espécie de contenção, de produção de limites que buscam entender a constituição do outro como diferente, e assim, compreender os sentidos socioculturais que geram a sua própria realidade, apesar de não se configurar propriamente como um modo de classificação. Como afirma Kuhn (1974) sobre a produção científica, a busca por uma 
verdade, a chamada ciência normal, implicou uma anulação de tudo aquilo que afastava-se dessa norma, reduzindo à verdade apenas àquilo vinculado ao paradigma vigente.

Assim, esta abordagem, como também o percurso de pesquisa do projeto Intercâmbio de Saberes $^{2}$, que deu origem à maior parte das pesquisas disponibilizadas pela MAterioteca, vincula-se a uma perspectiva decolonial e intersubjetiva, constituindo-se como plataformas de "contação" ${ }^{3}$ de saberes que não operam em divisão mas, em contrapartida, sinalizam abertura, expandindo as fronteiras dos sentidos das coisas, não dispensando a utilidade acadêmica e a enunciação das diferenças.

A resposta a essa problematização está nas histórias, as quais devem ser entendidas como o modo como as pessoas, as coisas e o meio ambiente, emaranhados em suas linhas de correspondência, negociam um caminho de movimento pelo mundo, conforme aponta Ingold $(2011 ; 2012 ; 2015 ; 2018)$.

$\mathrm{Na}$ forma de contar (NORONHA, 2020) de seu fazer com os materiais, cujo reconhecimento se torna tangível em meio digital e público, os artesãos e artesãs se articulam com a sociedade e as tecnologias heterônomas, preservando e fortalecendo a autopoiésis e as existências de suas comunidades (ESCOBAR, 2016).

Amplificando a potência das histórias, valoriza-se também outras construções de conhecimentos que não cumprem as prerrogativas dos saberes formalizados, exaltando uma maneira de conhecer o mundo ligada ao aprendizado por meio do responder às pessoas, ao meio e todas as coisas vivas que o constitui, numa relacionalidade intrínseca à prática, e que carrega em seu saberfazer uma forte ligação com a memória cultural e o reconhecimento de suas origens, aquilo que Escobar denomina por pluriverso:

\begin{abstract}
"Articula imaginação e tecnologia ontologicamente; reconceitua o "mundo" para criar possibilidades de futurização; e enfrenta a antropogênese da tecnicidade. [...] Sempre implica reconexão: com não-humanos; com as coisas em sua 'coisidade'; com a Terra (conexões sábias com a Terra); com o espírito; e, é claro, com os seres humanos em sua alteridade radical (decolonialmente, levando em consideração a inclusão de múltiplos mundos, e não sua exclusão). Contribui para desmantelar dualismos e leva a sério todas as formas não dualistas de existência. Oferece caminhos para (maior) conscientização e para ontologias de compaixão e cuidado." (ESCOBAR, 2016, p. 153-154).
\end{abstract}

Assim, opondo-se ao pensamento racional e dualista que impera dentro de um contexto científico normalizado, imaginamos outras formas de desenhar as relações travadas com os materiais. Numa perspectiva pluriversal, atende-se ao compromisso de reconhecer uma multiplicidade de saberes, perpassados por cosmologias outras, a fim de decolonizar nossos modos de ser, saber e fazer, e, portanto, atuar de maneira a articular novas formas de projetar no campo do design.

\footnotetext{
2 O projeto Intercâmbios de estratégias vernaculares de produção, promoção e comercialização do artesanato entre grupos de Alcântara e Baixada Maranhense, financiado pelo edital Tecnologias Sociais da FAPEMA (2015), teve como objetivo promover práticas colaborativas entre grupos produtivos de artesanato e trocas de tecnologias sociais. Os intercâmbios e anseios das comunidades nortearam a produção de cartografias, envolvendo estudantes de graduação e mestrado em Design da UFMA e corpo docente. As cartografias apresentam processos, saberes compartilhados, reflexões teóricas; são resultado e, ao mesmo tempo, abordagem metodológica da pesquisa.

${ }^{3}$ Contação é uma categoria nativa observada por Noronha durante pesquisa de campo com artesãs do quilombo de Itamatatiua e que visava a comunicação das características e qualidades da louça tradicional por elas produzidas. Mais sobre a categoria está no artigo "Conter e contar: relações de autonomia e autopoiésis entre mulheres, materiais e narrativas à luz de Design Anthropology", de autoria de Noronha e Abreu, aceito para publicação na revista Pensamentos em Design, da ED-UEMG .
} 


\section{Metodologia}

Primeiramente, deve-se ressaltar que o processo de desenvolvimento resultou de uma atividade colaborativa entre os integrantes da pesquisa, equipe que envolveu os pesquisadores do NIDA, no que concerne ao layout e revisão dos textos informativos dispostos no site da MAterioteca. Além disso, o projeto da MAterioteca sintetizou as pesquisas realizadas anteriormente pelo núcleo, as quais foram orientadas por meio de metodologias de colaboração com comunidades produtoras de artesanato maranhenses.

A plataforma assume, assim, um caráter de mediação e divulgação desses saberes artesanais mapeados através de práticas que envolveram o fazer "com" e não "para" a comunidade, pautadas na busca de um envolvimento mais próximo com as pessoas, na dissolução das hierarquias entre os agentes do projeto e na produção de modelos de inovação sustentáveis para o território, visando a autopoiésis aludida por Escobar (2016), em referência à Maturana e Varela (1987).

À vista disto, as etapas de construção do acervo se iniciou com o levantamento dos materiais e processos contemplados nas pesquisas do NIDA no curso de todos os anos de investigação nessas comunidades, principalmente, utilizando como referência as informações contidas no livro "Ciranda de Saberes: percursos cartográficos e práticas artesanais em Alcântara e na Baixada Maranhense" (2017) e diversos artigos de autoria de integrantes do núcleo. Baseando-se no material já produzido, investimos em pensar em como possibilitar a organização dessas informações dentro de uma estrutura que valorizasse os materiais e processos.

Logo, a partir da análise de outros acervos de âmbito nacional e internacional, pudemos compreender as diferentes formas de caracterização dos acervos digitais de materiais (SILVA, 2019). No exercício de avaliação, percebemos que, em sua maioria, os acervos se estruturam como grandes catálogos organizados em seções específicas, como polímeros, metais e cerâmicas, sendo a tipificação das materiotecas variáveis entre acadêmicas, independentes e comerciais (CAMPOS E DANTAS, 2008).

Os catálogos estão orientados na exibição de informações científicas sobre as especificidades físicas dos materiais, atrelados, por conseguinte, à exposição dos produtos que podem ser desenvolvidos com o uso de certo material ou como consequência de um processo. Entre os acervos investigados, encontram-se as materiotecas de caráter comercial, como a MateriaBrasil, acadêmico, como a Materialize (USP) e independente, exemplificada pela Material District, na Holanda. ${ }^{4}$

Constatou-se que os tipos de materiotecas se diferenciam em certos aspectos, como flexibilidade na disposição dos materiais, gratuidade, usabilidade, priorização de informações mais técnicas, exposição de propagandas, entre outros. Em síntese, os acervos analisados obedecem a uma categorização sistemática das propriedades observadas nas amostras, em sua maioria, muito distantes de uma formulação mais abrangente quanto aos saberes tácitos e não especializados em relação aos materiais.

Assim, prescreve-se uma série de informações técnicas, em que os materiais são tidos como unidades fechadas, inertes e desvinculadas das relações, tal como se preza dentro de um modelo de classificação.

No exercício de levantamento dos materiais e processos que seriam contemplados no acervo, definimos que estes seriam: fibra de buriti, sementes de juçara, cerâmica (barro), guarimã, coco babaçu, tingimentos naturais, caretas de cazumbá, renda de bilro, tecelagem de redes, bois de bumba, pilões, bordados de bois e bordados. A catalogação de acordo com o local de uso do material e/ou realização do processo também nos guiou como fator de organização de elementos que estão presentes em mais de um local do estado.

Inspiradas pelos modos de se entender as coisas imersas em um emaranhado de saberes narrativos e tácitos, imaginamos outros modos de sistematização para materialização do nosso acervo. Orientando-se na ideia de uma malha (INGOLD, 2011), compreendida como uma representação das coisas ao longo de um entrelaçamento de linhas de vida e não como pontos interconectados, partimos à elaboração do modo em que as informações sobre os materiais e processos se organizam no site.

A MateriaBrasil pode ser acessada em www.materiabrasil.com.br, a Materialize (USP), em www.materialize.fau.usp.br e a Material District, em www.materialdistrict.com. 
Figura 3 - Apresentação das dimensões sobre os materiais em forma de malha.

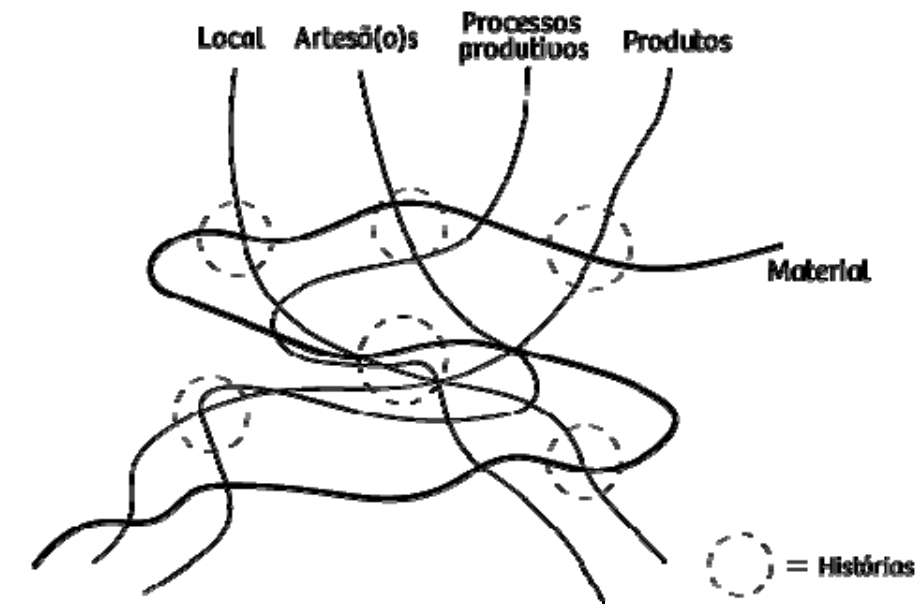

Fonte: Das autoras.

Como na noção de um emaranhamento de fios vitais, dispomos as informações sobre cada material e processo em local, artesã(o)s, processos produtivos e produtos de modo que o material, constantemente em fluxo, se revele como uma linha primordial que atravessa todos esses aspectos, criando nós de relação, isto é, as histórias frutos desse entrecruzamento. No desenho acima (Figura 3), o entrelaçar das linhas sugere que todos os tópicos expostos "vazam" para além de seus domínios, ou seja, cada aspecto deve ser considerado em meio às suas relações com todos os outros, pois não podem ser confinados como categorias inertes, desassociadas de seus movimentos de itineração pelo mundo, conforme disposto por Ingold (2012).

O contar dessas histórias, materializado na MAterioteca, se posiciona como um lugar de encontro entre essas dimensões, em que um exercício de correspondência é conduzido de forma a entremear, a partir dos materiais, as pessoas que fazem, o território, os processos e os produtos, todos em um contínuo estado de interdependência. Sendo assim, exercitamos uma nova forma de estruturação com a intenção de aproximar o modelo de sistematização de materiais/processos normalizado a uma prática mais atencional com os materiais que habitam o mundo, despertando reflexões sobre as possíveis relações que se operam nas ações de escolha e produção de artefatos com materiais em projetos no campo do design, por exemplo.

No que tange à etapa metodológica referente ao desenvolvimento da TIC, foram feitos testes de usabilidade a partir da criação de um modelo de fluxograma de navegação para o site, com o objetivo de analisar os procedimentos de interação entre o indivíduo e o produto sob aspectos técnicos e subjetivos, otimizando o uso da plataforma (SILVA, 2019). De acordo com Veloso et al. (2018), as TICs facilitam uma maior disseminação de informações, já que possibilitam que estas sejam acessadas de forma cómoda, instantânea e intuitiva, ampliando, dessa forma, os canais de difusão sobre conhecimentos históricos e culturais. Em um contexto cada vez mais globalizado, a inserção de práticas tradicionais no ambiente das tecnologias digitais favorece o acesso à cultura, a salvaguarda da identidade regional, o estímulo à valorização do artesanato e de suas cadeias produtivas dentro de um contexto local (VELOSO et al., 2018). 


\section{Resultados}

Ao acessar o acervo, pode-se considerar uma proximidade estrutural com uma configuração classificatória, baseando-se nas divisões que foram feitas conforme as definições de materiais e processos. É de conhecimento que a MAterioteca se assemelhe, à primeira vista, aos outros acervos de materiais tradicionais, embora se diferencie pela ausência de hierarquias que agrupam os materiais em classificações mais generalizadas, como, por exemplo, divisões entre materiais de caráter cerâmicos, metais, têxteis, entre outros.

Distingue-se também por priorizar a divulgação dos saberes e fazeres envolvidos na produção de artefatos artesanais em contraposição à apresentação de seus resultados, isto é, os produtos finalizados. A categorização do acervo se orienta unicamente por meio de uma forma de sinalização dos materiais e processos característicos do território maranhense, alguns deles divididos de acordo com a localidade em que se encontra, a citar o exemplo do material "Barro", o qual sofre uma ordenação baseada nos dois locais das pesquisas realizadas no NIDA sobre tal material: as comunidades de Itamatatiua e Porto dos Nascimentos.

A página inicial da plataforma já introduz o visitante a cenários e imaginários locais, através de uma série de slides de fotos, que revelam inicialmente a malha de pessoas, práticas e territórios maranhenses. Dessa forma, pretende-se encaminhar o visitante a outras histórias, preparando-o para a construção de um contato mais íntimo e um estreitamento de laços com esses saberes e fazeres, por meio de narrativas instigadas através das fotos mostradas. $\mathrm{O}$ visitante perpassa por esses imaginários e é levado a validar e reconhecer outros tipos de identidades, representações e formas de conhecimento.

Figuras 4 e 5 - Página inicial da MAterioteca e categorias da MAterioteca

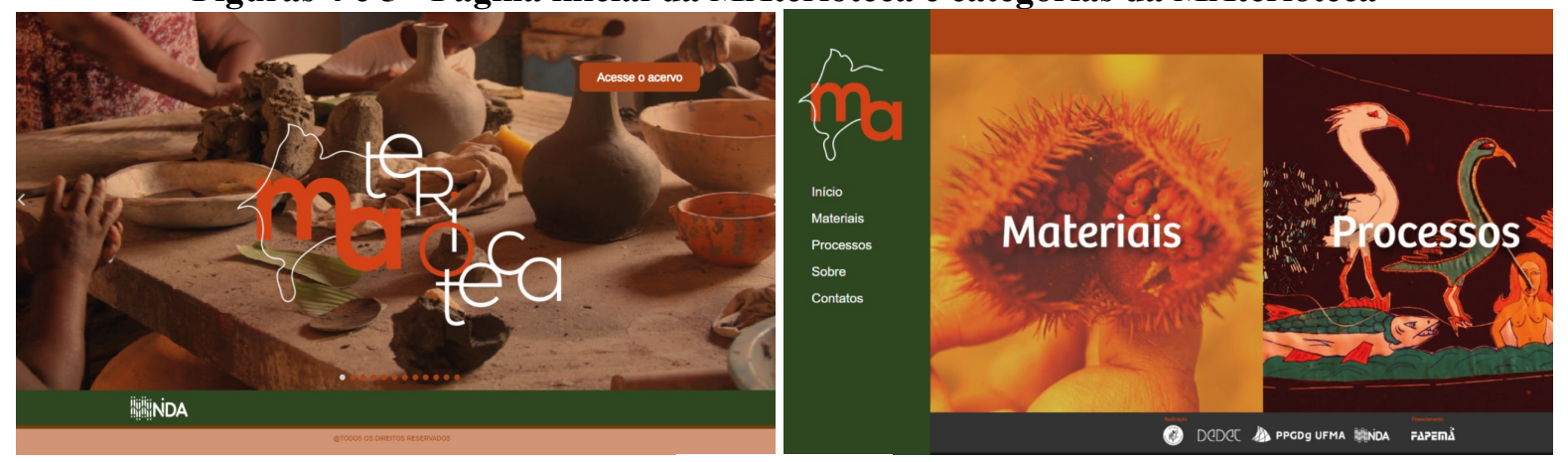

Fonte: autoras

Esta peculiaridade de estrutura denota uma distinção no tratamento de materiais e processos, contrariando-se à forma de disposição descritiva, como se concebe na ciência dos materiais e em disciplinas de projeto.

Ao focar apenas no produto final e em um aparato técnico e classificatório, o fazer desse material perde sua história envolvida, seu processo, seu território, seu contato com mãos e outras ferramentas, resultando, assim, na morte da forma, conforme Ingold (2012) descreve sobre a abordagem hilemórfica.

Inspiradas pelo autor, e pretendendo assumir uma perspectiva mais atencional enquanto designers, optou-se assumir o papel de mediar esse processo de trazer as coisas (nesse caso, os materiais e processos que estão presentes em nossa MAterioteca) de volta à vida (INGOLD, 2012), com foco nos fluxos de materiais, em que o sentido presente nesses saberes e fazeres não acadêmicos sejam materializados através de suas histórias e seu contato com o território, com a corporeidade atuante e outros processos vitais envolvidos. 

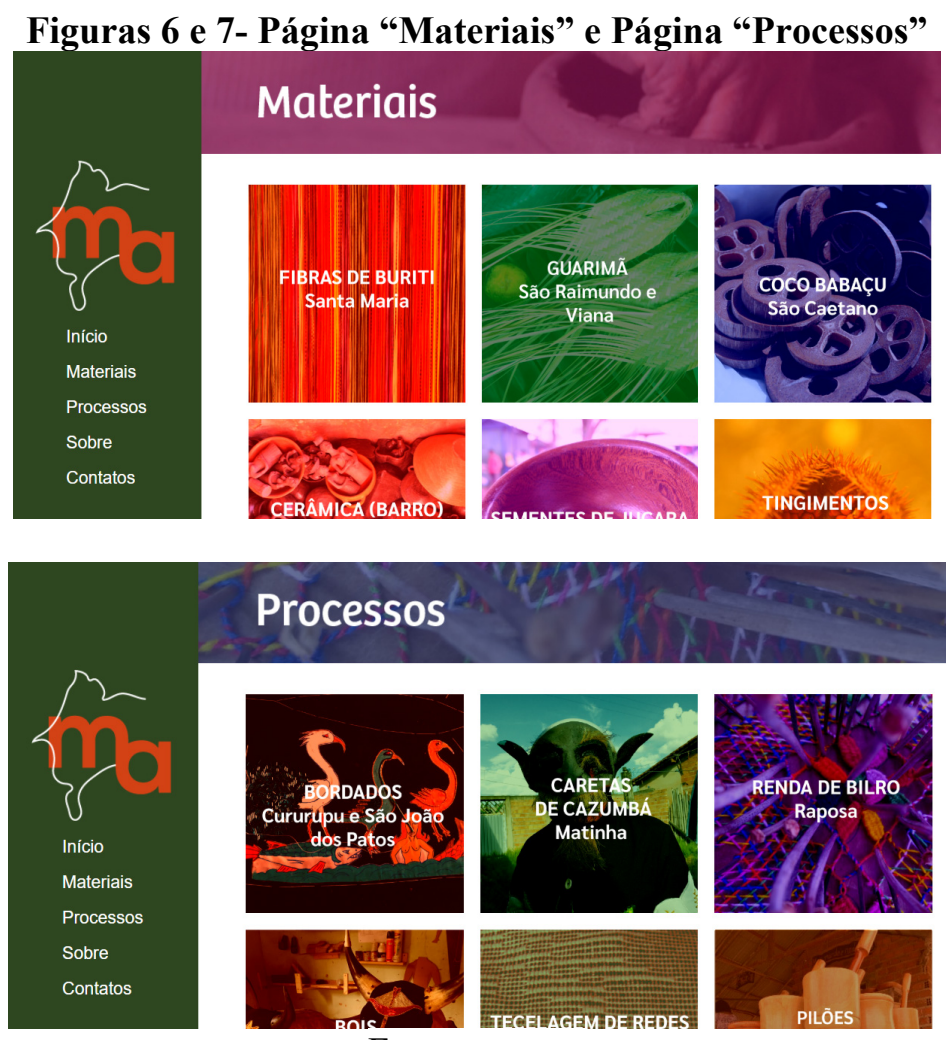

Fonte: autoras

Seguindo esse fluxo do autor citado, o foco da MAterioteca não é no objeto concreto e acabado em si, mas o seu durante, suas tramas de contato que geram emaranhados de linhas entre pessoas com outras pessoas, com os materiais, com as ações envolvidas e processos que façam sentido para aqueles que fazem e constroem isso juntos.

O web espaço da MAterioteca ganhou forma (sendo esta dinâmica, pois a plataforma será constantemente atualizada com novas histórias e pesquisas) e vida somente através do apoio e trabalho em conjunto de várias pessoas que fizeram e ainda vão fazer parte dessa construção compartilhada.

Para Ingold (2018), esse caminhar é acompanhado de uma postura atencional de se estar no mundo, postura essa que motivou as designers pesquisadoras do NIDA a darem materialidade ao site, possibilitando uma maior visibilidade de processos artesanais através das histórias por trás do emaranhado de nós que compõem a complexidade de cada fazer desenvolvido.

As sementes de juçara, por exemplo, não são meros frutos da juçareira que a constitui. A palmeira pode ser considerada um agregado de fios vitais, por conta de toda a vida e rastros que a compõe, tal como o processo de beneficiamento das sementes de juçara realizada no bairro do Maracanã, conforme a pesquisa realizada por Saraiva et al (2020) com as artesãs do lugar.

Figura 8 - Página "Sementes de juçara"

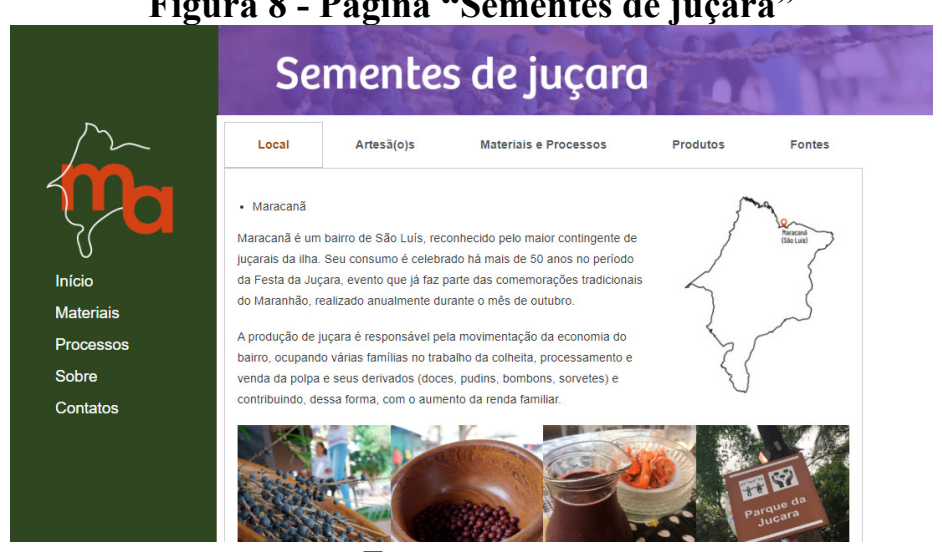

Fonte: autoras 
Dessa forma, com base na teoria de Ingold (2012), as coisas transpõem aquilo que podemos visualizar a um primeiro momento delas. As sementes, nesse caso, vazam para além daquela forma primária que as constituem. Elas são plantadas, colhidas, tratadas, manuseadas e desenvolvem relações de afeto e sentido para aqueles que realizam diferentes processos com elas.

Para além das histórias contadas, a plataforma objetiva por meio delas, estabelecer um fortalecimento dessa rede de afetos e ligações entre as práticas artesanais realizadas aqui no Maranhão e aqueles que se deixam tocar pelas práticas de correspondências geradas.

Nesse sentido, a plataforma da MAterioteca, sendo uma "coisa" na concepção de Ingold, também vazaria das telas virtuais para uma dimensão externa aos pixels, convidando os visitantes maranhenses (e também visitantes externos) a conhecer o próprio território e suas potências, as práticas locais, os saberes e fazeres compartilhados, assim, estimulando a valorização da cultura local e ancestral.

Acionamos as TICs, enquanto aliadas para esse processo de ponte entre designers, artesãos e visitantes da plataforma, para facilitar o acesso ao conhecimento das comunidades locais. Planejamos assim, enquanto designers, habitar o mundo, principalmente nosso próprio território, se juntando ao processo de formação desse emaranhado de coexistências e relações atencionais perante coisas, não apenas a produtos ou ideias pré-concebidas.

\section{Considerações finais}

A articulação rumo ao reconhecimento de uma pluralidade de saberes oferece um horizonte de possibilidades quanto ao aprendizado no campo do ensino do design. Além de ser um meio de fragmentar o ensino tradicional eurocentrado do design, desvinculado de seu meio e contexto local, os designers são instigados a investigar outras formas de se fazer design em seu próprio território, valorizando o conhecimento tácito e situando suas ações em práticas que incorpore malhas complexas e subjetividades.

Operar com diferentes mundos desmembra a manutenção do conhecimento e práticas funcionais deslocadas que ainda são muito sustentadas pelo design na contemporaneidade e também incentiva a validação de narrativas não acadêmicas. Trazer essas narrativas são formas de se praticar a decolonização do conhecimento (TUNSTALL, 2013), pois assim pode-se ampliar possibilidades de se especular novas formas imaginativas de aprender, fazer e representar no campo do design.

Outra possibilidade de futuro, que caminha juntamente à decolonização, é a perspectiva do bem viver, pautada na construção de uma sociedade que adote uma postura biocêntrica, que acredita que o meio ambiente e todos os seus seres possuem valor ontológico e devem caminhar juntamente à humanidade, num âmbito comunitário (ESCOBAR, 2016). Numa dinâmica de reconhecimento da multiplicidade, considera-se como "outros" também outras formas de vida, nesse caso, os materiais.

Ao julgar que os materiais, na verdade, caminham em fluxo, são unidades vivas e não podem ser percebidos de forma afastada de contextos, nos aproximamos do bem viver, reconhecendo a existência de outros seres. Portanto, como discorrido anteriormente neste artigo, as dimensões que atravessam o material, como o local, as pessoas que fazem, os processos produtivos e os resultados desses processos, precisam ser entendidos numa relação de correspondência.

O designer trabalha diretamente com os materiais, possui interferência direta na produção de produtos e deve ser responsável por tratar questões materiais pensando na convivência em harmonia com a natureza daquele território, numa perspectiva mais sustentável. Expandindo a visão em direção à constituição de uma comunidade entre as coisas, nos tornamos mais conscientes sobre as formas que projetamos e sobre nosso papel em meio a um cenário de exacerbação produtiva guiada por ideias de desenvolvimento extremamente prejudiciais para os territórios e as pessoas que o habitam, as quais contribuem para a desfuturização e anulam as linhas de relacionalidade entre os agentes.

Especulando sobre o pluriverso, Escobar declara que "cada ferramenta e tecnologia é ontológica no sentido de que, por mais humilde ou insignificante que seja, inaugura uma série de rituais, modos de fazer e modos de ser" (ESCOBAR, 2016, p. 128). A noção de que projetar coisas envolve, conjuntamente, a projetação de formas de ser convoca a possibilidade de um design que abranja o projetar de múltiplos modos de ser, um espaço onde o pluriverso suscite de modo a abarcar 
diferenças e relações entre os seres humanos, o território e o fluxo de materiais, entrelaçados entre si e não separados, como num modelo de classificação.

A tarefa assumida pelo projeto da MAterioteca em meio a esse emaranhado de interrelações foi, portanto, de mediar os processos de sentido, as várias cosmologias imbricadas no fazer artesanal, de modo a tornar tangível à sociedade um acervo com os materiais que os artesãos utilizam para criar seus mundos. Assim, potencializando os espaços para a construção de outros mundos, os artesãos e artesãs contam as suas histórias, que se desenrolam por meio dos processos de fazer com os materiais, e possibilitam o entendimento de outras formas de relacionalidade.

Materials, artisans' knowledge and pluriversal practices in the construction of a virtual "MAterioteca"

Abstract: The article in question proposes a reflection on the practices about materials in the field of design, from the construction of a virtual "MAterioteca", a collection of materials (DANTAS AND BERTOLDI, 2016) for the recognition of artisans' knowledge from Maranhão. Engaging in a dialogue with the British anthropologist Tim Ingold (2011), it triggers the concepts of classificatory knowledge and narrative knowledge linked to the notion of tacit knowledge (SPINUZZI, 2005) in order to speculate about the decoloniality of knowledge (TUNSTALL, 2013) and practices oriented to the pluriverse (ESCOBAR, 2016), topics that serve for the analysis exercise on the methodology used and the results materialized in the collection. Finally, it elaborates pluriversal possibilities in the relations with the materials in order to exercise the valorization of a multiplicity of knowledge and ontologies.

Keywords: MAterioteca; handicrafts; narrative knowledge; tacit knowledge; pluriverse

\section{Referências Bibliográficas}

ANASTASSAKIS, Zoy. Triunfos e Impasses: Lina Bo Bardi, Aloisio Magalhães e o design no Brasil. Rio de Janeiro: Lamparina Editora, 2014.

ASHBY, M. F. \& JOHNSON, K. Materials and design: the art and science of material selection in product. Oxford: Elsevier, 2002.

CUNHA, Manuela Carneiro da. Relações e dissensões entre saberes tradicionais e saber científico. In: Cultura com aspas e outros ensaios. São Paulo: Cosac Naify, 2009. p. 301-310.

DANTAS, Denise; BERTOLDI, Cristiane Aun. Sistema de catalogação e indexação de amostras de materiais orientado a projetos de design para uso em materiotecas. São Paulo: DAT Journal Design Art and Technology. Transdisciplinarity: Projects, Materials, and Processes, set. 2016, v.1, n.2, p.62-75. DOI: https://doi.org/10.29147/dat.v1i2. Disponível em: https://datjournal.anhembi.br/dat/article/view/29/22. Acesso em: set. 2020.

DANTAS, D.; CAMPOS, A. P. Análise Comparativa de Materiotecas: recomendações para a construção de modelos acadêmicos. In: 80. Congresso Brasileiro de Pesquisa e Desenvolvimento em Design / P\&D Design 2008, 2008, São Paulo. Anais do Oitavo Congresso Brasileiro de Pesquisa e Desenvolvimento em Design / P\&D 2008. São Paulo: Aend Brasil, 2008. p. 56-72.

ESCOBAR, Arturo. Autonomia y diseño: la realización de lo comunal. Popayán: Editorial Universidad del Cauca, 2016

INGOLD, Tim. Being Alive: essays on movement, knowledge, and description. London: Routledge, 2011.

INGOLD, Tim. Trazendo as coisas de volta à vida: emaranhados criativos num mundo de matérias. Porto Alegre: Horizontes Antropológicos, jan. 2012, ano 18, n. 37, p. 25-44. Disponível em: 
http://www.scielo.br/scielo.php?script=sci_arttext\&pid=S0104-71832012000100002. Acesso em: set. 2020.

INGOLD, Tim. The life of lines. Abingdon: Routledge, 2015.

INGOLD, Tim. Anthropology and/as Education. Abingdon: Routledge, 2018

KARANA, Elvin. How do materials obtain their meanings? Turkey: Metu Jfa, 2010. p. 271-285.

KUHN, T. S. Structure of Scientific Theories. Urbana: University of Illinois Press, 1974.

LEITE, João de Souza. Aloisio Magalhães: Aventura paradoxal no design brasileiro; ou o Design como instrumento civilizador? Tese (Doutorado em Ciências Sociais) - Rio de Janeiro: Faculdade de Ciências Sociais, Instituto de Filosofia e Ciências Humanas, Universidade do Estado do Rio de Janeiro, 2006.

LIMA, Julyana; NORONHA, Raquel; SANTOS, Denilson. Materiais que geram novos materiais: uma percepção simbólica sobre os compósitos. In: Anais do $13^{\circ}$ Congresso Pesquisa e

Desenvolvimento em Design (2018), p. 36-48. São Paulo: Blucher, 2019.

MANZINI, Ezio. Design, when everybody design: an introduction to Design for Social innovation. Cambridge/London: The MIT Press, 2015.

MATURANA, Humberto; VARELA, Francisco. The tree of knowledge: the biological roots of human understanding. Berkeley: Shambhala, 1987.

MAUSS, Marcel. Sociologia e Antropologia. São Paulo: Cosac Naif, 2003.

NORONHA, Raquel Gomes. Dos quintais às prateleiras: as imagens quilombolas e a produção de louça em Itamatatiua - Alcântara - Maranhão. São Luís: EDUFMA, 2020.

NORONHA, Raquel; SOLIS, Gloriana. Aprendiendo con los materiales: encuentro de diseñadoras y artesanos por medio de correspondencias. Chile: RChD: Creación y Pensamiento, nov. 2019, v. 4, n.7, p. 1-15. DOI: http://dx.doi.org/10.5354/0719-837X.2019.53828. Disponível em:

https://revistas.uchile.cl/index.php/RChDCP/article/view/53828. Acesso em: set. 2020.

NORONHA, Raquel et al. Cirandas de saberes: percursos cartográficos e prática artesanal em Alcântara e Baixada Maranhense. São Luís: EDUFMA, 2017.

NORONHA, Raquel Gomes. Era uma vez no quilombo: narrativas sobre turismo, autenticidade e tradição entre artesãs de Alcântara (MA). Rio de Janeiro: Textos Escolhidos de Cultura e Arte Populares (TECAP), mar. 2015, v.12, n.1, p. 43-60. DOI: http://dx.doi.org/

10.12957/tecap.2015.16351. Disponível em: https://www.e-

publicacoes.uerj.br/index.php/tecap/article/view/16351. Acesso em: set. 2020.

NORONHA, Raquel Gomes. (Org.). Identidade é valor: as cadeias produtivas do artesanato de Alcântara. São Luís: EDUFMA, 2011.

SARAIVA, Gisele Correa dos Reis; SANTOS, Tayomara Santos dos; NORONHA, Raquel Gomes. Juçara da minha cor: reconhecendo e valorizando o território. São Luís: EDUFMA, 2020.

SILVA, Alice Campos et al. Correspondências entre saberes: construindo uma MAterioteca virtual com artesãos maranhenses. In: Anais do III Simpósio Internacional Interdisciplinar em Cultura e Sociedade - PGCULT. São Luís: EDUFMA, 2020. p. 423-442.

SILVA, Campos Alice. Desenvolvimento de uma materioteca virtual: construção do reconhecimento dos saberes das comunidades artesãs maranhenses. 2019. Trabalho de Conclusão de Curso (Bacharelado em Design) - São Luís: Universidade Federal do Maranhão, 2019.

SPINUZZI, Clay. The methodology of participatory design. Washington: Technical Communication, mai. 2005, v. 52, n.2, p. 163-174. Disponível em:

https://repositories.lib.utexas.edu/bitstream/handle/2152/28277/SpinuzziTheMethodologyOfParticipat oryDesign.pdf?sequence=2. Acesso em: set. 2020.

TUNSTALL, Elizabeth Dori. Decolonizing Design Innovation: design anthropology and indigenous knowledge. In: GUNN, Wendy; OTTO, Tom; SMITH, R. C. Design Anthropology: Theory and Practice. London: Bloomsbury, 2013. p. 232-250. 
VELOSO, Gabrielli Ciasca; TRIERWEILLER, Andréa Cristina; ESTEVES, Paulo César Leite. As Tics como suporte ao patrimônio público cultural: Projeto de digitalização do acervo do arquivo histórico do município de Araranguá-SC. São Paulo: RDBCI: Revista Digital Biblioteconomia e Ciência da Informação, set. 2017, v.16, n. 1, p. 25-38. DOI: https://doi.org/10.20396/rdbci.v16i1.8648773. Disponível em: https://periodicos.sbu.unicamp.br/ojs/index.php/rdbci/article/view/8648773/pdf. Acesso em set. 2020. 